\title{
Alteration of the fecal microbiota in Chinese patients with Schistosoma japonicum infection
}

Yanyan Jiang ${ }^{1,2,3,4}$, Zhongying Yuan ${ }^{1,2,3,4}$, Yujuan Shen ${ }^{1,2,3,4}$, Bruce A. Rosa ${ }^{5}$, John Martin ${ }^{5}$, Shengkui Cao ${ }^{1,2,3,4}$, Yanjiao Zhou ${ }^{6}$, Makedonka Mitreva ${ }^{5,7, *}$, and Jianping Cao ${ }^{1,2,3,4, *}$

${ }^{1}$ National Institute of Parasitic Diseases, Chinese Center for Disease Control and Prevention, 200025 Shanghai, PR China

${ }^{2}$ Chinese Center for Tropical Diseases Research, 200025 Shanghai, PR China

${ }^{3}$ World Health Organization Collaborating Centre for Tropical Diseases, 200025 Shanghai, PR China

${ }^{4}$ Key Laboratory of Parasite and Vector Biology, National Health Commission of the People's Republic of China, 200025 Shanghai, PR China

${ }^{5}$ McDonnell Genome Institute, Washington University in St Louis, St Louis, 63001 MO, USA

${ }^{6}$ Department of Medicine, UConn Health, Farmington, 06023 CT, USA

${ }^{7}$ Division of Infectious Diseases, Department of Medicine, Washington University School of Medicine, St Louis, 63001 MO, USA

Received 31 July 2020, Accepted 14 December 2020, Published online 8 January 2021

\begin{abstract}
Schistosoma japonicum infection causes pathological injury to the host. Multiple studies have shown that intestinal helminth infection causes dysbiosis for the gut microbial community and impacts host immunology. However, the effect of acute S. japonicum infection on the gut microbiome structure (abundance and diversity) is still unclear. We collected fecal samples from healthy and infected patients from a single hospital in Hunan Province, China. The bacterial community was analyzed using 16S ribosomal RNA gene sequencing of the V4 hypervariable region using the HiSeq platform. Compared with healthy subjects, infected patients exhibited an increase in relative abundance of the TM7 phylum. At the genus level, there were seven differentially abundant genera between groups. The most significant finding was a Bacteroides enterotype in patients with acute schistosomiasis. These results suggest that $S$. japonicum infection has a significant effect on microbiome composition characterized by a higher abundance of the TM7 phylum and development of a Bacteroides enterotype.
\end{abstract}

Key words: Schistosoma japonicum, 16s rDNA, Infectious disease, Fecal microbiome, Enterotype.

Résumé - Altération du microbiote fécal chez les patients chinois atteints d'une infection à Schistosoma japonicum. L'infection à Schistosoma japonicum provoque des lésions pathologiques chez l'hôte. Plusieurs études ont montré qu'une infection intestinale par les helminthes provoque une dysbiose de la communauté microbienne intestinale et a un impact sur l'immunologie de l'hôte. Cependant, l'effet de l'infection aiguë à S. japonicum sur la structure du microbiome intestinal (abondance et diversité) n'est toujours pas clair. Nous avons collecté des échantillons fécaux de patients sains et infectés dans un hôpital de la province du Hunan, en Chine. La communauté bactérienne a été analysée par séquençage du gène de l'ARN ribosomal $16 \mathrm{~S}$ de la région hypervariable V4 en utilisant la plateforme HiSeq. Par rapport aux sujets sains, les patients infectés ont présenté une augmentation de l'abondance relative du phylum TM7. Au niveau du genre, il y avait sept genres différentiellement abondants entre les groupes. La découverte la plus significative était un entérotype Bacteroides chez les patients atteints de schistosomiase aiguë. Ces résultats suggèrent que l'infection à $S$. japonicum a un effet significatif sur la composition du microbiome caractérisé par une plus grande abondance du phylum TM7 et le développement d'un entérotype Bacteroides.

\section{Introduction}

Schistosomiasis remains a devastating and highly prevalent neglected tropical disease that is endemic mainly in poor and undeveloped regions [50]. Of the three major pathogenic species causing schistosomiasis, Schistosoma japonicum is responsible for human and animal infections in parts of East and Southeast Asia, primarily China, the Philippines, and Indonesia [58]. Adult S. japonicum worms inhabit the mesenteric veins of the gut and trigger a cellular immune response

*Corresponding authors: caojp@yahoo.com; mmitreva@wustl.edu

This is an Open Access article distributed under the terms of the Creative Commons Attribution License (https://creativecommons.org/licenses/by/4.0), which permits unrestricted use, distribution, and reproduction in any medium, provided the original work is properly cited. 
in the host when eggs are released, which leads to a wide range of clinical manifestations including gut inflammation [25]. This calso affects the gut microbiota [28].

The human gut is colonized by an enormous community of microbes, termed the microbiota [8], which impacts the host immune system. The gut microbiota interacts with interleukin-17 to induce $\mathrm{T}$ helper cell differentiation in the lamina propria of the small intestine to drive autoimmune disease [53]; the microbiota also provides resistance to colonization by enteric pathogens [4]. Alterations in the human microbiome have been associated with a range of conditions in the developed world, including diabetes [55], non-alcoholic fatty liver disease (NAFLD) [45], inflammatory bowel disease (IBD), cardiovascular disease, cancer [3], and refractory Clostridium difficile infection [38]. Microbiome changes have been observed in people with parasitic nematode infections, including higher relative abundance of Paraprevotellaceae in patients infected with Trichuris trichiura [34] and an increased abundance of Sphingobacteria, Deltaproteobacteria, and Erysipelotrichia after deworming [44]. Moreover, these microbiome changes have been observed in children with parasitic protozoa infections [23, 40, 52]. Children [32] and adults [1] infected with $S$. haematobium had altered gut microbiota, urogenital schistosomiasis, and altered bladder pathologies. In addition, a mouse model of $S$. mansoni infection showed that depletion of gut bacteria resulted in a reduction in schistosome egg excretion, an alteration in the specific immune response [28], and an alteration in inflammatory response and gut pathology caused by specific bacteria [30].

Studies analyzing the effect of $S$. japonicum infection on the gut microbiota are lacking. We directly addressed this issue by examining the intestinal microbial community during acute S. japonicum infection, and identifying associations between bacteria and enterotypes with acute schistosomiasis in an epidemic area of China.

\section{Materials and methods}

\section{Ethics statement}

All experiments were approved by the Ethics Committee of the National Institute of Parasitic Diseases, Chinese Center for Disease Control and Prevention (No. 2015-011). All participants were informed of the objectives, procedures and potential risks of the study. Written informed consent forms were personally signed by all adult subjects. The personal information of all the participants has been kept confidential.

\section{Subjects and sample collection}

Twenty-six participants living in the same geographical area were included in this cross-sectional study (Table 1 ). They were local male fishermen without hepatitis B or $\mathrm{C}$ infections, who had not received any medical therapy within the previous three months. All of the study participants were $>30$ years old, and had no other parasitic infection. The study was conducted between September and December 2016.

Eleven patients were initially screened for Schistosoma spp. eggs in feces using the Kato-Katz method [31] and by quantifying levels of indirect hemagglutination antibody (IHA) in the serum. They also had a fever or fatigue accompanied by tenderness in the liver region, and had been in contact with cercariae in water in the previous three months. They had no other helminth eggs (e.g., hookworm, roundworm, whipworm, pinworm, or Taenia) according to microscopic examination, but fecal samples were found to contain Schistosoma spp. eggs. Moreover, molecular examinations were not indicative of any emerging and important protozoa (such as Blastocystis spp., Giardia intestinalis, Entamoeba spp., Cryptosporidium spp., Enterocytozoon bieneusi, and Cyclospora cayetanensis). After sample collection, all infected patients were treated with praziquantel.

The 15 healthy subjects (control) did not display clinical symptoms of schistosome infection and yielded negative laboratory results according to the Kato-Katz method and IHA test, and they had no history of schistosomiasis.

A total of 26 fresh fecal samples (15 controls, 11 patients) were stored in $2.0-\mathrm{mL}$ Eppendorf tubes and frozen at $-80{ }^{\circ} \mathrm{C}$ until DNA extraction.

\section{DNA extraction}

DNA was extracted from a frozen aliquot $(200 \mathrm{mg})$ of each fecal sample using a QIAamp DNA Mini Stool Kit (Qiagen, Valencia, CA, USA). DNA concentration was measured by a Qubit 2 (Invitrogen) and its molecular size was estimated by agarose gel electrophoresis. DNA libraries were constructed according to the manufacturer's instructions (Illumina). The $\mathrm{V} 4$ region of the $16 \mathrm{~S}$ rDNA gene was amplified using the $515 \mathrm{~F}$ forward $\left(5^{\prime}-\right.$ GTGCCAGCMGCCGCGGTAA - 3') and 806R reverse primers $\left(5^{\prime}-\right.$ GGACTACHVGGGTWTCTAAT $-3^{\prime}$ ) (BGI company, China). Sequencing was performed using Illumina HiSeq (Illumina, paired end, 250 bp reads).

\section{Analytical processing and annotation of the $16 \mathrm{~S}$ rRNA sequences}

Sequence reads were joined using fastq-join and quality filtered (phred score $Q \geq 25$ ). Sequences were assembled using the FLASh assembler [36]. Assembled reads were filtered to remove sequences shorter than $200 \mathrm{bp}$ and any sequences containing fewer than $42 \mathrm{~N}$-free 8-mers. Chimera sequences were identified and removed using ChimeraSlayer, with default parameters [16]. As a result, the total dataset comprised approximately 0.9 million reads, and the number of reads of individual samples ranged from 30,387 to 40,304. Taxonomic calls were assigned using the classify.seqs program with the Mothur 16S rRNA gene data processing pipeline [46]. The Ribosomal Database Project Naïve Bayesian Classifier (version 2.5 with training set 9 [9]) (Release9 201203[10]) was used with a 0.5 confidence level. Reads with $<0.5$ confidence of classification was considered to be "unclassified" at a given taxonomical level.

\section{Statistical analysis}

Microbiota richness was determined using the Chao1 index and Shannon's diversity index. These indices were calculated with QIIME and displayed with R software (version 2.15.3), and the Kruskal-Wallis test was used for comparison between 
Table 1. Participant profiles.

\begin{tabular}{|c|c|c|c|c|c|c|}
\hline \multirow[t]{2}{*}{ No. participant } & \multirow[t]{2}{*}{ Age (year) } & \multirow[t]{2}{*}{ Group } & \multirow[t]{2}{*}{ Kato-Katz method } & \multicolumn{3}{|c|}{ IHA } \\
\hline & & & & $1: 2$ & $1: 10$ & $1: 20$ \\
\hline SJ_1 & 57 & $\geq 50$-year-old & + & - & + & + \\
\hline SJ_2 & 48 & $<50$-year-old & + & - & + & - \\
\hline SJ_3 & 52 & $\geq 50$-year-old & + & - & + & - \\
\hline SJ_4 & 39 & $<50$-year-old & + & - & + & - \\
\hline SJ_5 & 46 & $<50$-year-old & + & - & + & + \\
\hline SJ_6 & 44 & $<50$-year-old & + & - & + & + \\
\hline SJ_7 & 49 & $<50$-year-old & + & + & - & - \\
\hline SJ_8 & 48 & $<50$-year-old & + & + & - & - \\
\hline SJ_9 & 52 & $\geq 50$-year-old & + & - & + & + \\
\hline SJ_10 & 66 & $\geq 50$-year-old & + & + & - & - \\
\hline SJ_11 & 48 & $<50$-year-old & + & + & - & - \\
\hline C_1 & 58 & $\geq 50$-year-old & - & - & - & - \\
\hline C_2 & 46 & $<50$-year-old & - & - & - & - \\
\hline C_3 & 50 & $\geq 50$-year-old & - & - & - & - \\
\hline C_ 4 & 64 & $\geq 50$-year-old & - & - & - & - \\
\hline C_5 & 51 & $\geq 50$-year-old & - & - & - & - \\
\hline C_6 & 42 & $<50$-year-old & - & - & - & - \\
\hline C_7 & 59 & $\geq 50$-year-old & - & - & - & - \\
\hline C_8 & 45 & $<50$-year-old & - & - & - & - \\
\hline C_9 & 56 & $\geq 50$-year-old & - & - & - & - \\
\hline $\mathrm{C}_{-} 10$ & 59 & $\geq 50$-year-old & - & - & - & - \\
\hline C_11 & 68 & $\geq 50$-year-old & - & - & - & - \\
\hline C_12 & 56 & $\geq 50$-year-old & - & - & - & - \\
\hline C_13 & 60 & $\geq 50$-year-old & - & - & - & - \\
\hline C_14 & 67 & $\geq 50$-year-old & - & - & - & - \\
\hline C_-15 & 42 & $<50$-year-old & - & - & - & - \\
\hline
\end{tabular}

groups. Beta diversity analysis (i.e., differences in samples in terms of bacterial community composition) was visualized using Principal Coordinates Analysis (PCoA) with the "cmdscale" function in R. Samples were clustered according to relative taxa abundance values across all taxa (i.e., read counts normalized by total reads mapped per sample) with the "hclust" function in R to interpret the distance matrix using complete linkage. DESeq2 was used to identify specific taxa that are significantly different between patients and healthy subjects [35] (unpaired differential analysis) in R for abundance testing of differential taxa. DESeq2 was the preferred approach based on its negative binomial statistical design and high performance over a full range of effect sizes, replicate numbers, and library sizes [39]. All DESeq2 input data (read counts) and output results are available in Supplemental Table 1. The phylum level comparison between the healthy participants and the patients was done with the Wilcox rank sum test. Enterotype assignment, encoded as "ET_B" (Bacteroides enriched), "ET_P" (Prevotella enriched), and "ET_F" (Firmicutes enriched), were generated using the classification tool (http://enterotypes.org/) and are independent of de novo clustering. Differences were considered significant if the $p$-value was $<0.05$ using the chi-square test. Figures were prepared using GraphPad Prism software, version 6.

\section{Results}

\section{Characteristics of the study population}

Eleven subjects were diagnosed with acute schistosomiasis based on positive Schistosoma egg and IHA tests; 15 participants were healthy subjects from the same area (controls). All participants were between 39 and 68 years old, and they were divided according to age into the $\geq 50$-year-old group and the $<50$-year-old group. They could be divided into three groups based on the serum IHA test results (Table 1).

\section{Microbial communities by host infection status}

A total of 939,453 quality-filtered reads were obtained for an average of 34,795 reads per sample. Reads were clustered into 419 unique genera and assigned to 27 bacterial phyla. The Chaol index - which is used to estimate the total number of observed species in each community - indicated that there was no significant difference between the healthy controls and infected subjects (Fig. 1A). The Shannon diversity index which indicates the diversity of species in every sample was also not significantly different between the assessed groups (Fig. 1B). Principal coordinate analysis (PCoA) of the fecal microbial communities showed strong clustering of the samples by individual rather than infection status, age group, or IHA test result (Figs. 1C-1E). This suggests that the microbial community composition in each subject remained relatively stable regardless of $S$. japonicum infection status.

\section{Differentially abundant taxa}

Proteobacteria and Firmicutes were the dominant phyla in the fecal microbial communities of both groups (Fig. 2A). The mean relative abundance of the top five phyla in infected subjects and healthy controls based on the Wilcoxon rank 
A

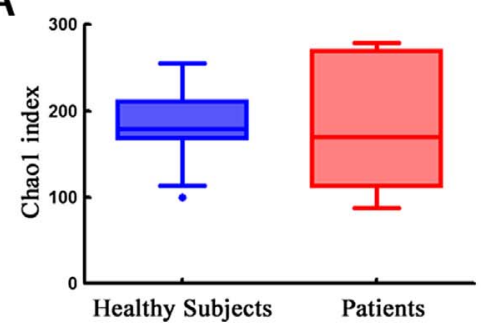

B

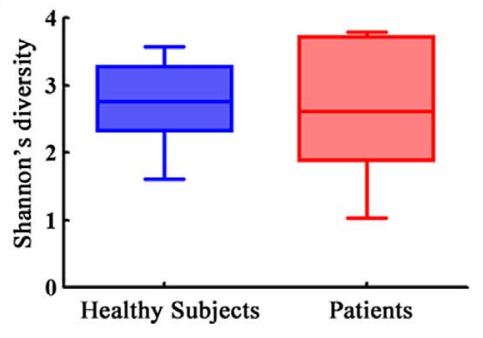

C

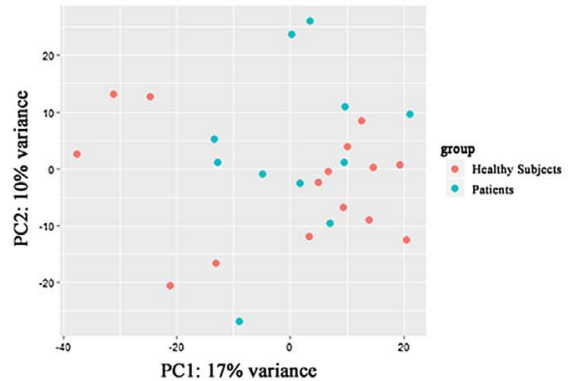

D

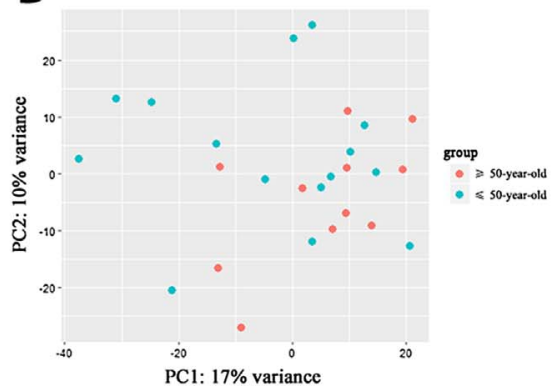

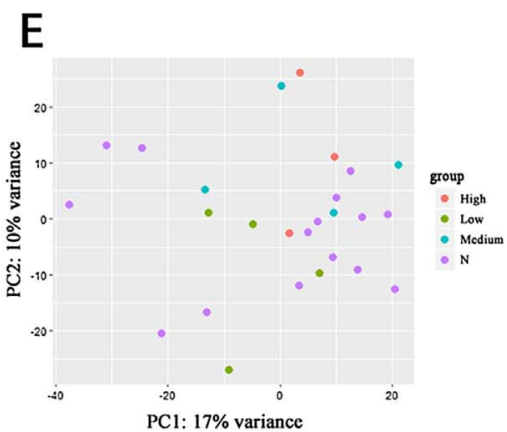

Figure 1. Relative abundance of bacterial phyla in infected patients $(n=11)$ and healthy controls $(n=15)$. (A) No significant differences were observed in the mean community richness as estimated by the Chaol index. (B) No significant differences were observed in the mean community richness as estimated by the Shannon diversity index. (C) Principal coordinate analysis of the microbial communities in healthy controls and acute schistosomiasis patients using unweighted UniFrac distances by infection status (C), by age group (D), and indirect hemagglutination antibody (IHA) levels (E).

sum statistical comparison were: Proteobacteria $(52.7 \%$ versus $55.6 \%$ in infected subjects and healthy controls, respectively, $p=0.38, p$-value $>0.05)$, Firmicutes $(41.2 \%$ vs. $31.1 \%$ in infected subjects and healthy controls, respectively, $p=0.13$, $p$-value $>0.05)$, Acidobacteria $(1.6 \%$ vs. $4.3 \%$ in infected subjects and healthy controls, respectively, $p=0.06$, $p$-value $>0.05)$, Cyanobacteria/Chloroplast (1.5\% vs. $1.0 \%$ in infected subjects and healthy controls, respectively, $p=0.27$, $p$-value $>0.05$ ), and TM7 (which is synonymous with Saccharibacteria [7] based on genome comparison [11, 42] and is referred to as TM7 in this study for comparison with the reference) (1.0\% vs. $5.9 \%$ in infected subjects and healthy controls, respectively, $p=0.003, p$-value $<0.01$ ) (Fig. 2B).

At the genus level, there were seven differentially abundant genera. Five genera (Comamonas, Psychrobacter, Clostridium, Veillonella, and Butyricimonas) had significantly lower relative abundance in infected patients than in the healthy controls (adjusted $p$-value $<0.05$ ); meanwhile, two genera (Methylophilus and Turicibacter) had significantly higher relative abundance in infected patients than in the healthy controls (adjusted $p$-value <0.05) (Fig. 3A and Table 2).

\section{Detection of the gut microbial enterotypes in healthy subjects and patients}

Some reports have indicated that enterotypes provide a new perspective for microbial markers related to certain diseases or specific host traits [54]. Based on online enterotype classification and compared with large-scale projects such as MetaHIT and HMP [2,33], enterotypes were significantly differentially distributed between healthy subjects and acute schistosomiasis patients (chi-square test for independence: $n=26, \chi^{2}=6.61$, $p=0.037$ ), with the patients harboring the unique Bacteroides enterotype. A comparison between healthy subjects and acute schistosomiasis patients was made in Figure 3B.

\section{Discussion}

This study is the first description of gut microbiota changes in $S$. japonicum-infected patients in an epidemic area in China by high-throughput $16 \mathrm{~S}$ rDNA gene sequencing. Comparing the alpha diversity index using Kruskal-Wallis tests, the Chaol index and Shannon diversity index, no significant differences were observed between patients and healthy subjects. Although these data were the same as for subjects infected with S. haematobium and controls [1], the relatively small sample size was a limitation of our study, and may have affected the statistical power to identify minor changes in the fecal microbiota following $S$. japonicum infection. However, our most intriguing finding was that there was a higher proportion of TM7 and a Bacteroides-rich enterotype in patients with acute $S$. japonicum infection than in healthy controls.

As a unique phylum, TM7, which exhibited an increase in relative abundance in acute $S$. japonicum infected patients, has not previously been linked to schistosome infection [47]. TM7 is globally distributed and is often associated with human inflammatory mucosal diseases. In particular, TM7 is a kind of oral resident bacteria [14] that is dominant in cases of intra-oral halitosis [48]. Cultivation of a human-associated TM7 phylotype revealed a complete lack of capacity for amino acid biosynthesis; this suggests a potential for immune suppression through the repression of TNF-alpha production 
A

Phylum

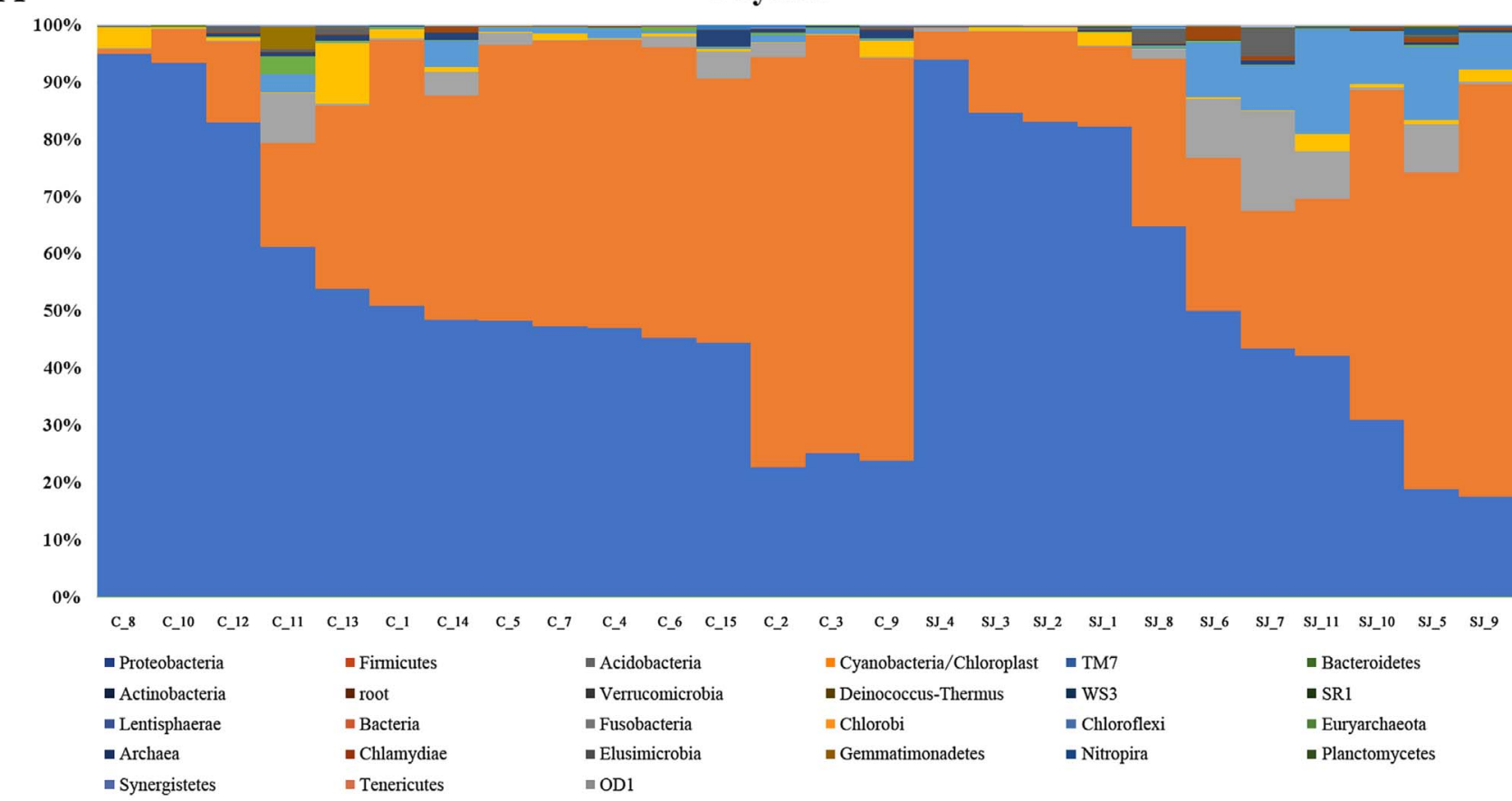

B

Phylum

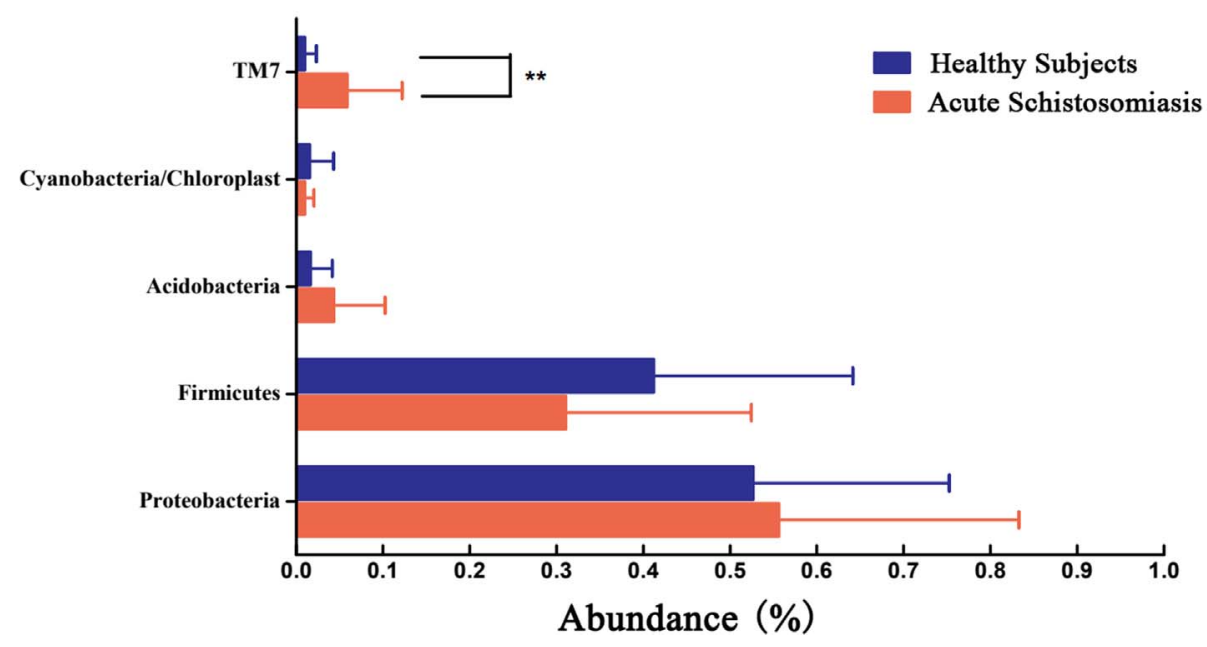

Figure 2. Differences in microbial community structure at the phylum level. (A) Proteobacteria and Firmicutes were the dominant phyla in both groups. (B) Significant difference in the relative abundance of TM7 between healthy controls and infected subjects.

in macrophages [26]. Other studies have shown that periodontal disease is a risk factor for human colorectal cancer [41], and have identified orally associated bacteria as biomarkers for cancer. Therefore, compared with our data, we suggest that the increase in the relative abundance of TM7 may be a novel biomarker associated with $S$. japonicum infection.

In our study, Proteobacteria and Firmicutes were the most altered phyla in response to $S$. japonicum infection; this is consistent with previous studies [37]. An increasing amount of data identifies Proteobacteria as a possible microbial signature of disease [43]. Proteobacteria are present in various human body sites, including the skin, oral cavity, tongue, vaginal tract, and gut [12], and were found to be correlated with the genesis of endotoxemia and in the development of metabolic disorders [49]. It is possible that alterations in $\mathrm{pH}$, bile flow, ratio of obligate anaerobes to facultative anaerobes, and intestinal hormone levels influence the abundance of Proteobacteria in the feces [27]. Specifically, some researchers consider Methylophilus to be an aerobic, methanol-utilizing bacteria [19] that utilizes a number of organic carbon compounds for growth; additionally, it has traditionally been regarded as one of the most important saccharolytic species and expresses multiple anti-oxidative enzymes [18]. In addition, it has also been linked to the stimulation of TNF production in vitro from peripheral blood mononuclear cells of healthy patients, as well as a higher circulating $\operatorname{IgG}$ response in patients affected by 
A

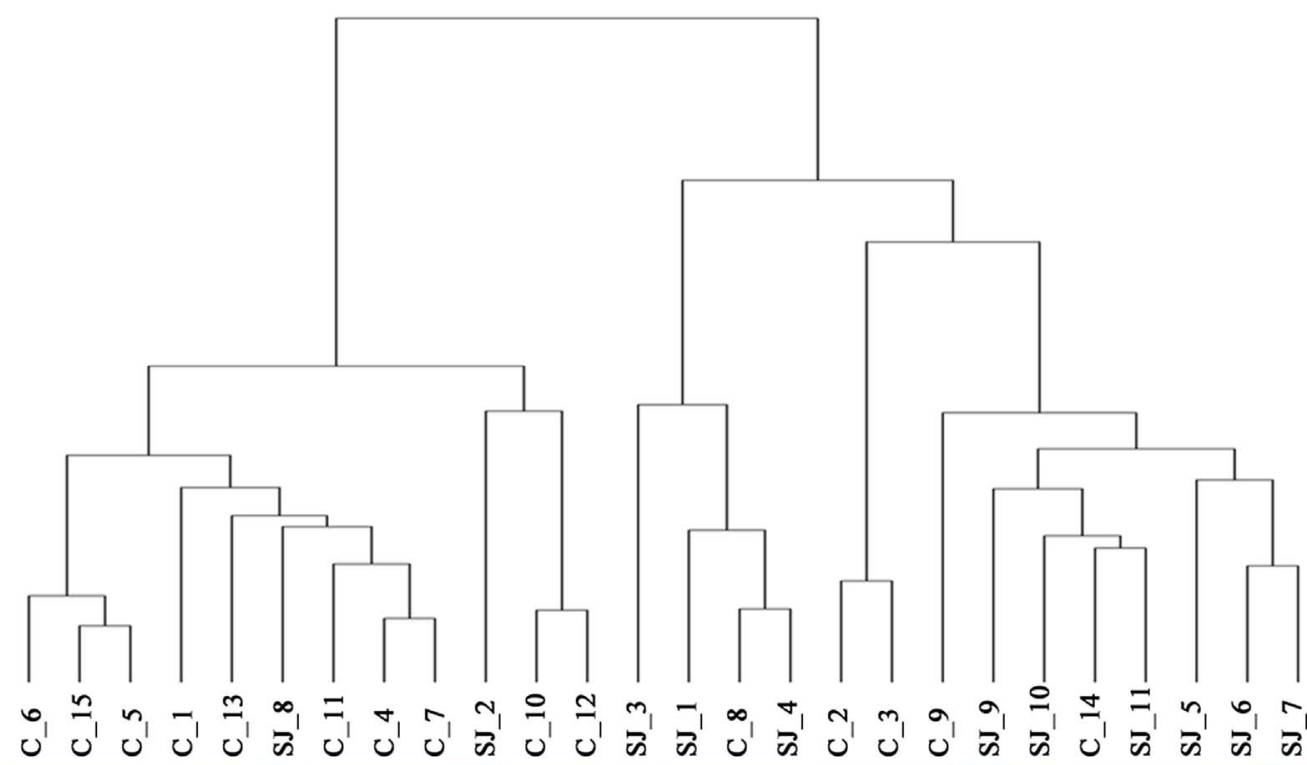

ET
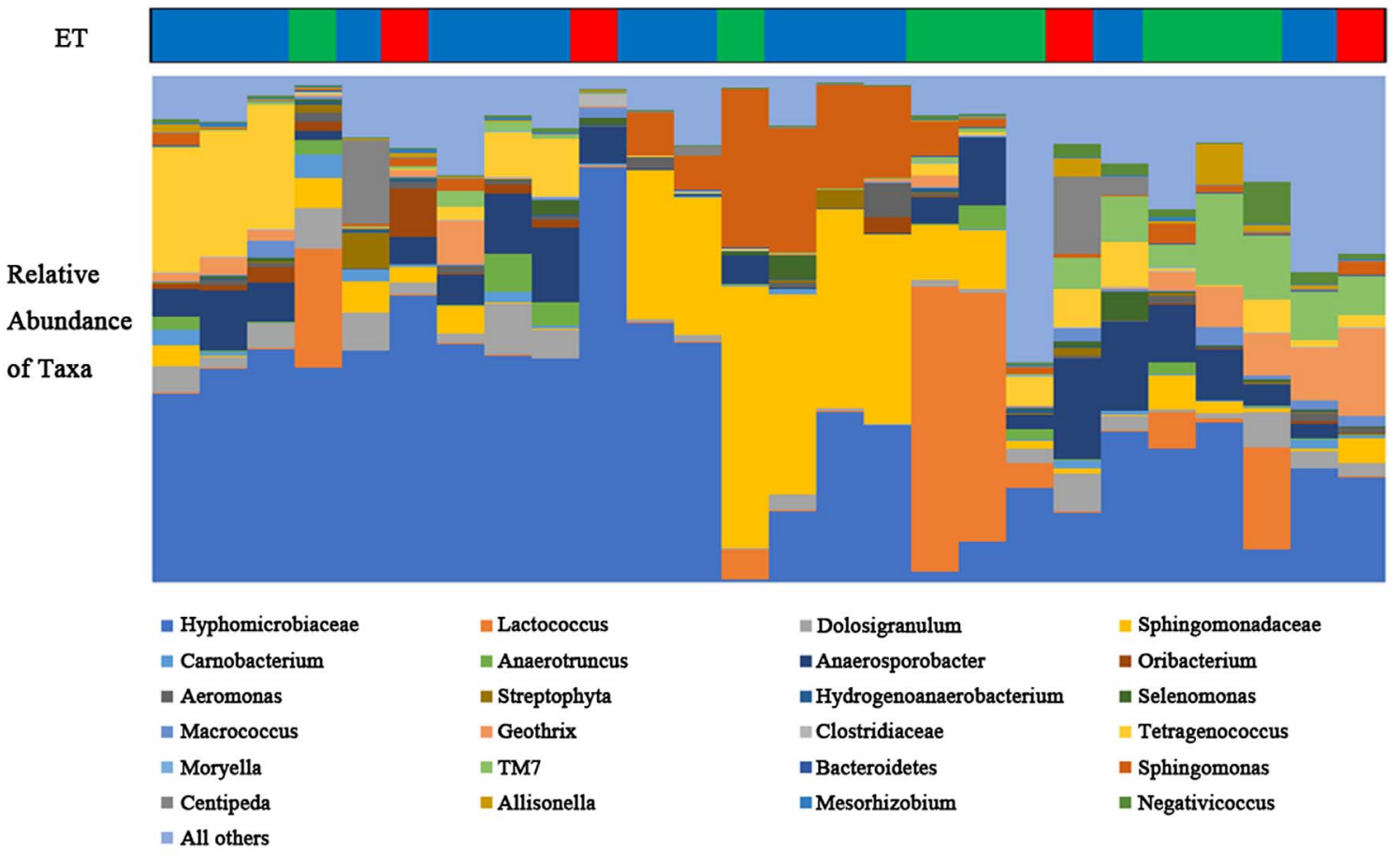

$\mathrm{B}$

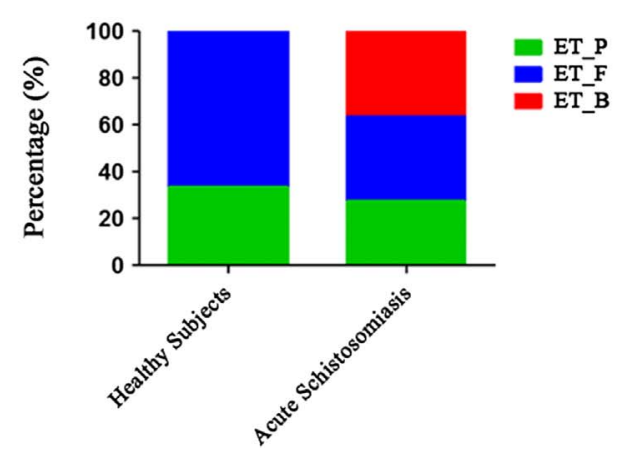

Figure 3. Bar chart showing the composition of the relative abundant bacterial groups and enterotype of each subject at the genus level. (A) Relative abundant bacterial of taxa in each subject according to the Euclidean distance metric and "Complete" linkage of cluster. (B) distribution of healthy subjects and acute schistosomiasis patients over three enterotypes: Prevotella (ET_P, $n=8)$, Firmicutes (ET_F, $n=14$ ), and Bacteroides (ET_B, $n=4$ ). Chi-square test for independence: $n=26, \chi^{2}=6.61, p=0.037$. 
Table 2. The relative abundance of differentially abundant taxa based on DESeq2 analysis.

\begin{tabular}{|c|c|c|c|c|c|c|c|c|c|}
\hline \multirow[t]{2}{*}{ Phylum } & \multirow[t]{2}{*}{ Class } & \multirow[t]{2}{*}{ Order } & \multirow[t]{2}{*}{ Family } & \multirow[t]{2}{*}{ Genus } & \multicolumn{2}{|c|}{ Average abundance } & \multirow{2}{*}{$\begin{array}{c}\text { Adjusted } \\
p \text {-value }\end{array}$} & \multirow{2}{*}{$\begin{array}{l}\text { Sig. higher } \\
\text { with } \\
\text { Schisto }\end{array}$} & \multirow{2}{*}{$\begin{array}{c}\text { Sig. lowe } \\
\text { with } \\
\text { Schisto }\end{array}$} \\
\hline & & & & & $\begin{array}{l}\text { Healthy } \\
\text { subjects }\end{array}$ & patients & & & \\
\hline Proteobacteria & Betaproteobacteria & Methylophilales & Methylophilaceae & Methylophilus & $1.93 \mathrm{E}-05$ & $2.07 \mathrm{E}-05$ & $1.62 \mathrm{E}-03$ & & $\mathrm{Y}$ \\
\hline Firmicutes & Erysipelotrichia & Erysipelotrichales & Erysipelotrichaceae & Turicibacter & $3.21 \mathrm{E}-05$ & $8.51 \mathrm{E}-04$ & $2.98 \mathrm{E}-02$ & & $\mathrm{Y}$ \\
\hline Bacteroidetes & Bacteroidia & Bacteroidales & Porphyromonadaceae & Butyricimonas & $6.17 \mathrm{E}-03$ & $9.73 \mathrm{E}-04$ & $7.96 \mathrm{E}-03$ & $\mathrm{Y}$ & \\
\hline Proteobacteria & Betaproteobacteria & Burkholderiales & Comamonadaceae & Comamonas & $2.08 \mathrm{E}-03$ & $2.26 \mathrm{E}-06$ & $1.62 \mathrm{E}-03$ & $\mathrm{Y}$ & \\
\hline Proteobacteria & Gammaproteobacteria & Pseudomonadales & Moraxellaceae & Psychrobacter & $1.07 \mathrm{E}-03$ & $2.26 \mathrm{E}-06$ & $1.37 \mathrm{E}-02$ & $\mathrm{Y}$ & \\
\hline Firmicutes & Erysipelotrichia & Erysipelotrichales & Erysipelotrichaceae & Clostridium & $1.63 \mathrm{E}-03$ & $1.22 \mathrm{E}-03$ & $1.37 \mathrm{E}-02$ & $\mathrm{Y}$ & \\
\hline Firmicutes & Negativicutes & Selenomonadales & Veillonellaceae & Veillonella & $2.32 \mathrm{E}-02$ & $9.52 \mathrm{E}-03$ & $1.25 \mathrm{E}-02$ & $\mathrm{Y}$ & \\
\hline
\end{tabular}

inflammatory bowel disease $[5,18]$. This might indicate that the abundance of Methylophilus in infected patients in our study is the result of an inflammatory response to acute schistosomiasis. We also found that the relative abundance of Comamonas and Psychrobacter were significantly decreased in infected patients. Comamonas is an obligate aerobe [51]. Psychrobacter is a kind of cold adapted bacteria that can help to moderate temperature for other bacteria and enzymes $[15,17]$ to maintain a suitable environment for infection. The alterations in the relative abundance of these three genera of Proteobacteria suggest that $S$. japonicum infection induces a systemic inflammation response, possibly by potentially highly efficient xenobiotic metabolizing species.

The relative abundance of Turicibacter was increased in infected patients, which suggests it may be involved in the development of systemic inflammation through alterations in immune cell activation [24]. However, the relative abundance of Clostridium, Butyricimonas and Veillonella were decreased in infected patients. Some studies have reported that decreased levels of Clostridium are correlated with total cholesterol levels [22], which suggests that these taxa may play a role in the infection through effects on lipid metabolism. In addition, the relative abundance of Butyricimonas and Veillonella have been reported to be negatively correlated with the severity of a number of diseases [20]. Thus, the alterations to the relative abundance of these taxa show that the microbiota is correlated with changes in metabolism and immune response during $S$. japonicum infection.

The identification of gut microbial clusters in the two groups was confirmed in our study. There are at least three gut microbial enterotypes, dominated by Bacteroides, Faecalibacterium (classified as Ruminococcus at the time), or Prevotella [13]. Similarly, we found one cluster of fecal communities that was distinguished by Bacteroides levels in acute schistosomiasis patients. This enterotype has been linked to alterations in nutrient processing, and also corresponds with the presence of genes that code for enzymes such as proteases, hexoaminidases, and galactosidases [29]. Growing evidence supports the notion that Bacteroides activate an infectious response in the intestine [6] and they were significantly more abundant in a mouse model of $S$. mansoni infection [30]. Based on the altered immune response in acute $S$. japonicum infection [56] and the data from mouse gut microbial modulation after infection with $S$. japonicum cercaria [57], future studies should examine whether the shift in enterotypes is associated with the
Bacteroides enterotype as a possible biomarker for acute schistosomiasis [21].

\section{Conclusions}

In this study, we identified differentially abundant taxa in the gut microbiota of infected subjects and healthy controls, which may be associated with inflammation in patients with acute schistosomiasis. Further studies are required to unveil the functional roles conserved in these significantly altered taxa, to determine the interspecies interactions with the gut microbiota of patients with acute schistosomiasis, to determine the interactions between gut microbiota members and $S$. japonicum, as well as with host, and to determine the link between systemic inflammation, alterations in fecal microbiota structure, and disease activity.

Acknowledgements. We would like to thank Professor Yongkang $\mathrm{He}$ for help with collecting samples at the Hunan Institute of Schistosomiasis Control, China.

\section{Data availability statement}

The raw sequencing data from 16S rRNA gene sequencing used in this study are available in the short reads archive (SRA) database (accession number PRJNA625383).

\section{Author contributions}

Yanyan Jiang and Jianping Cao designed the study. Jianping Cao contributed reagents and materials. Yanyan Jiang, Zhongying Yuan, Yujuan Shen, and Shengkui Cao performed the experiments. Yanyan Jiang, Makedonka Mitreva, Bruce A. Rosa, John Martin, and Jianping Cao analyzed and interpreted the data. Yanyan Jiang wrote the manuscript. Jianping Cao, Makedonka Mitreva, Bruce A. Rosa, and Yanjiao Zhou revised the manuscript. The authors declare that there are no conflicts of interest.

\section{Funding}

This study was funded by the National Natural Science Foundation of China (Nos. 81772225 and 81971969 to JC), 
the National Key Research and Development Program of China (No. 2017YFD0501300 to YJ) and the Chinese Special Program for Scientific Research of Public Health (No. 201502021 to JC). The funders had no role in study design, data collection and analysis, decision to publish, or preparation of the manuscript.

\section{Supplementary material}

Supplementary material is available at https://www.parasitejournal.org/10.1051/parasite/2020074/olm

Table S1. Bacterial taxa associated with healthy subjects and patients at the phylum and genus levels.

\section{References}

1. Adebayo A, Suryavanshi M, Bhute S, Agunloye A, Isokpehi R, Anumudu C, Shouche Y. 2017. The microbiome in urogenital schistosomiasis and induced bladder pathologies. PLoS Neglected Tropical Diseases, 11(8), e0005826.

2. Arumugam M, Raes J, Pelletier E, Le Paslier D, Yamada T, Mende DR, Fernandes GR, Tap J, Bruls T, Batto JM, Bertalan M, Borruel N, Casellas F, Fernandez L, Gautier L, Hansen T, Hattori M, Hayashi T, Kleerebezem M, Kurokawa K, Leclerc M, Levenez F, Manichanh C, Nielsen HB, Nielsen T, Pons N, Poulain J, Qin J, Sicheritz-Ponten T, Tims S, Torrents D, Ugarte E, Zoetendal EG, Wang J, Guarner F, Pedersen O, de Vos WM, Brunak S, Doré J, Antolín M, Artiguenave F, Blottiere HM, Almeida M, Brechot C, Cara C, Chervaux C, Cultrone A, Delorme C, Denariaz G, Dervyn R, Foerstner KU, Friss C, van de Guchte M, Guedon E, Haimet F, Huber W, van HylckamaVlieg J, Jamet A, Juste C, Kaci G, Knol J, Lakhdari O, Layec S, Le Roux K, Maguin E, Mérieux A, Melo Minardi R, M'rini C, Muller J, Oozeer R, Parkhill J, Renault P, Rescigno M, Sanchez $\mathrm{N}$, Sunagawa S, Torrejon A, Turner K, Vandemeulebrouck G, Varela E, Winogradsky Y, Zeller G, Weissenbach J, Ehrlich SD, Bork P. 2011. Enterotypes of the human gut microbiome. Nature, 473(7346), 174-180.

3. Ashton JJ, Colquhoun CM, Cleary DW, Coelho T, Haggarty R, Mulder I, Batra A, Afzal NA, Beattie RM, Scott KP, Ennis S. 2017. 16S sequencing and functional analysis of the fecal microbiome during treatment of newly diagnosed pediatric inflammatory bowel disease. Medicine (Baltimore), 96(26), e7347.

4. Bäckhed F, Ley RE, Sonnenburg JL, Peterson DA, Gordon J. 2005. Host-bacterial mutualism in the human intestine. Science, 307(5717), 1915-1920.

5. Blais Lecours P, Marsolais D, Cormier Y, Berberi M, Haché C, Bourdages R, Duchaine C. 2014. Increased prevalence of Methanosphaera stadtmanae in inflammatory bowel diseases. PloS One, 9(2), e87734.

6. Bloom SM, Bijanki VN, Nava GM, Sun L, Malvin NP, Donermeyer DL, Dunne WM, Allen PM, Stappenbeck TS. 2011. Commensal Bacteroides species induce colitis in hostgenotype-specific fashion in a mouse model of inflammatory bowel disease. Cell Host \& Microbe, 9(5), 390-403.

7. Bor B, Bedree JK, Shi W, McLean JS, He X. 2019. Saccharibacteria (TM7) in the human oral microbiome. Journal of Dental Research, 98(5), 500-509.

8. Chow J, Lee SM, Shen Y, Khosravi A, Mazmanian S. 2010. Host-bacterial symbiosis in health and disease. Advances in Immunology, 107, 243-274.
9. Cole J, Chai B, Farris R, Wang Q, Kulam-Syed-Mohideen A, McGarrell D, Bandela A, Cardenas E, Garrity G, Tiedje J. 2007. The ribosomal database project (RDP-II): introducing myRDP space and quality controlled public data. Nucleic Acids Research, 35, D169-D172.

10. Cole JR, Wang Q, Fish JA, Chai B, McGarrell DM, Sun Y, Brown CT, Porras-Alfaro A, Kuske CR, Tiedje JM. 2014. Ribosomal Database Project: data and tools for high throughput rRNA analysis. Nucleic Acids Research, 42(Database issue), D633-D642.

11. Collins AJ, Murugkar PP, Dewhirst FE. 2019. Complete genome sequence of strain AC001, a novel cultured member of the human oral microbiome from the candidate Phylum Saccharibacteria (TM7). Microbiology Resource Announcements, 8(42), e01158-19.

12. Consortium H M P. 2012. Structure, function and diversity of the healthy human microbiome. Nature, 486(7402), 207-214.

13. Costea PI, Hildebrand F, Arumugam M, Bäckhed F, Blaser MJ, Bushman FD, de Vos WM, Ehrlich SD, Fraser CM, Hattori M, Huttenhower C, Jeffery IB, Knights D, Lewis JD, Ley RE, Ochman H, O'Toole PW, Quince C, Relman DA, Shanahan F, Sunagawa S, Wang J, Weinstock GM, Wu GD, Zeller G, Zhao L, Raes J, Knight R, Bork P. 2018. Enterotypes in the landscape of gut microbial community composition. Nature Microbiology, 3(1), 8-16.

14. Dewhirst FE, Chen T, Izard J, Paster BJ, Tanner AC, Yu WH, Lakshmanan A, Wade WG. 2010. The human oral microbiome. Journal of Bacteriology, 192(19), 16.

15. Dias LM, Folador ARC, Oliveira AM, Ramos RTJ, Silva A, Baraúna R. 2018. Genomic architecture of the two cold-adapted genera Exiguobacterium and Psychrobacter: evidence of functional reduction in the Exiguobacterium antarcticum B7 Genome. Genome Biology and Evolution, 10(3), 731-741.

16. Edgar RC, Haas BJ, Clemente JC, Quince C, Knight R. 2011. UCHIME improves sensitivity and speed of chimera detection. Bioinformatics, 27(16), 2194-2200.

17. Fornbacke M, Clarsund M. 2013. Cold-adapted proteases as an emerging class of therapeutics. Infectious Diseases and Therapy, 2(1), 15-26.

18. Gaci N, Borrel G, Tottey W, O’Toole PW, Brugère J. 2014. Archaea and the human gut: new beginning of an old story. World Journal of Gastroenterology, 20(43), 16062-16078.

19. Gogleva AA, Kaparullina EN, Doronina NV, Trotsenko Y. 2010. Methylophilus flavus sp. nov. and Methylophilus luteus sp. nov., aerobic, methylotrophic bacteria associated with plants. International Journal of Systematic and Evolutionary Microbiology, 60, 2623-2628.

20. Gong J, Qiu W, Zeng Q, Liu X, Sun X, Li H, Yang Y, Wu A, Bao J, Wang Y, Shu Y, Hu X, Bellanti JA, Zheng SG, Lu Y, Lu Z. 2018. Lack of short-chain fatty acids and overgrowth of opportunistic pathogens define dysbiosis of neuromyelitis optica spectrum disorders: a Chinese pilot study. Multiple Sclerosis, $25,1352458518790396$.

21. Gorvitovskaia A, Holmes S, Huse S. 2016. Interpreting Prevotella and Bacteroides as biomarkers of diet and lifestyle. Microbiome, 4, 15.

22. Gózd-Barszczewska A, Kozioõõl-Montewka M, Barszczewski P, Mõõlodzińska A, Humińska K. 2017. Gut microbiome as a biomarker of cardiometabolic disorders. Annals of Agricultural and Environmental Medicine, 24(3), 416-422.

23. Guernier V, Brennan B, Yakob L, Milinovich G, Clements A, Soares MR. 2017. Gut microbiota disturbance during helminth infection: Can it affect cognition and behaviour of children? BMC Infectious Diseases, 17(1), 58.

24. Gülden E, Chao C, Tai N, Pearson JA, Peng J, MajewskaSzczepanik M, Zhou Z, Wong FS, Wen L. 2018. TRIF deficiency protects non-obese diabetic mice from type 1 diabetes by 
modulating the gut microbiota and dendritic cells. Journal of Autoimmunity, 93, 57-65.

25. Hams E, Aviello G, Fallon P. 2013. The schistosoma granuloma: friend or foe? Frontiers in Immunology, 4, 89.

26. He X, McLean JS, Edlund A, Yooseph S, Hall AP, Liu SY, Dorrestein PC, Esquenazi E, Hunter RC, Cheng G, Nelson KE, Lux R, Shi W. 2015. Cultivation of a human-associated TM7 phylotype reveals a reduced genome and epibiotic parasitic lifestyle. Proceedings of the National Academy of Sciences of the United States of America, 112(1), 244-249.

27. Henson MA, Phalak P. 2017. Microbiota dysbiosis in inflammatory bowel diseases: in silico investigation of the oxygen hypothesis. BMC Systems Biology, 11(1), 145.

28. Holzscheiter M, Layland LE, Loffredo-Verde E, Mair K, Vogelmann R, Langer R, Wagner H, Prazeres da Costa C. 2014. Lack of host gut microbiota alters immune responses and intestinal granuloma formation during schistosomiasis. Clinical and Experimental Immunology, 175(2), 246-257.

29. Jandhyala SM, Talukdar R, Subramanyam C, Vuyyuru H, Sasikala M, Nageshwar RD. 2015. Role of the normal gut microbiota. World Journal of Gastroenterology, 21(29), 87878803.

30. Jenkins TP, Peachey LE, Ajami NJ, MacDonald AS, Hsieh MH, Brindley PJ, Cantacessi C, Rinaldi G. 2018. Schistosoma mansoni infection is associated with quantitative and qualitative modifications of the mammalian intestinal microbiota. Scientific Reports, 8(1), 12072.

31. Katz N, Chaves A, Pellegrino J. 1972. A simple device for quantitative stool thick-smear technique in Schistosomiasis mansoni. Revista do Instituto de Medicina Tropical de São Paulo, 14(6), 397-400.

32. Kay GL, Millard A, Sergeant MJ, Midzi N, Gwisai R, Mduluza T, Ivens A, Nausch N, Mutapi F, Pallen M. 2015. Differences in the faecal microbiome in Schistosoma haematobium infected children vs. uninfected children. PLoS Neglected Tropical Diseases, 9(6), e0003861.

33. Koren O, Knights D, Gonzalez A, Waldron L, Segata N, Knight R, Huttenhower C, Ley RE. 2013. A guide to enterotypes across the human body: meta-analysis of microbial community structures in human microbiome datasets. PLoS Computational Biology, 9(1), e1002863.

34. Lee SC, Tang MS, Lim YA, Choy SH, Kurtz ZD, Cox LM, Gundra UM, Cho I, Bonneau R, Blaser MJ, Chua KH, Loke P. 2014. Helminth colonization is associated with increased diversity of the gut microbiota. PLoS Neglected Tropical Diseases, 8(5), e2880.

35. Love M, Huber W, Anders S. 2014. Moderated estimation of fold change and dispersion for RNA-seq data with DESeq2. Genome Biology, 15(12), 550.

36. Magoč T, Salzberg S. 2011. FLASH: fast length adjustment of short reads to improve genome assemblies. Bioinformatics (Oxford, England), 27(21), 2957-2963.

37. Maharshak N, Ringel Y, Katibian D, Lundqvist A, Sartor RB, Carroll IM, Ringel-Kulka T. 2018. Fecal and mucosa-associated intestinal microbiota in patients with diarrhea-predominant irritable bowel syndrome. Digestive Diseases and Sciences, 63(7), 1890-1899.

38. Mahmoodpoor F, Rahbar Saadat Y, Barzegari A, Ardalan M, Zununi Vahed S. 2017. The impact of gut microbiota on kidney function and pathogenesis. Biomedicine \& Pharmacotherapy, 93, 412-419.

39. McMurdie PJ, Holmes S. 2014. Waste not, want not: Why rarefying microbiome data is inadmissible. PLoS Computational Biology, 10(4), e1003531.
40. Mejia R, Damania A, Jeun R, Bryan P, Vargas P, Juarez M, Cajal P, Nasser J, Krolewiecki A, Lefoulon E, Long C, Drake E, Cimino R, Slatko B. 2020. Impact of intestinal parasites on microbiota and cobalamin gene sequences: a pilot study. Parasites \& Vectors, 13(1), 200.

41. Momen-Heravi F, Babic A, Tworoger SS, Zhang L, Wu K, Smith-Warner SA, Ogino S, Chan AT, Meyerhardt J, Giovannucci E, Fuchs C, Cho E, Michaud DS, Stampfer MJ, Yu YH, Kim D, Zhang X. 2017. Periodontal disease, tooth loss and colorectal cancer risk: results from the Nurses' Health Study. International Journal of Cancer, 140(3), 646-652.

42. Murugkar PP, Collins AJ, Dewhirst FE. 2019. Complete genome sequence of strain pm004, a novel cultured member of the human oral microbiome from the candidate Phylum Saccharibacteria (TM7). Microbiology Resource Announcements, 8(42), e01159-19.

43. Rizzatti G, Lopetuso LR, Gibiino G, Binda C, Gasbarrini A. 2017. Proteobacteria: a common factor in human diseases. BioMed Research International, 9351507, 7.

44. Rosa BA, Supali T, Gankpala L, Djuardi Y, Sartono E, Zhou Y, Fischer K, Martin J, Tyagi R, Bolay FK, Fischer PU, Yazdanbakhsh M, Mitreva M. 2018. Differential human gut microbiome assemblages during soil-transmitted helminth infections in Indonesia and Liberia. Microbiome, 6(1), 33.

45. Safari Z, Gérard P. 2019. The links between the gut microbiome and non-alcoholic fatty liver disease (NAFLD). Cellular and Molecular Life Sciences, 76(8), 1541-1558.

46. Schloss PD, Westcott SL, Ryabin T, Hall JR, Hartmann M, Hollister EB, Lesniewski RA, Oakley BB, Parks DH, Robinson CJ, Sahl JW, Stres B, Thallinger GG, Van Horn DJ, Weber CF. 2009. Introducing mothur: open-source, platform-independent, community-supported software for describing and comparing microbial communities. Applied and Environmental Microbiology, 75(23), 7537-7541.

47. Schneeberger PHH, Coulibaly JT, Panic G, Daubenberger C, Gueuning M, Frey JE, Keiser J. 2018. Investigations on the interplays between Schistosoma mansoni, praziquantel and the gut microbiome. Parasites \& Vectors, 11(1), 168.

48. Seerangaiyan K, van Winkelhoff AJ, Harmsen HJM, Rossen JWA, Winkel E. 2017. The tongue microbiome in healthy subjects and patients with intra-oral halitosis. Journal of Breath Research, 11(3), 036010.

49. Sgambato D, Miranda A, Romano L, Romano M. 2017. Gut microbiota and gastric disease. Minerva Gastroenterologica e Dietologica, 63(4), 345-354.

50. Sun LP, Wang W, Zuo YP, Zhang ZQ, Hong QB, Yang GJ, Zhu HR, Liang YS, Yang HT. 2017. An integrated environmental improvement of marshlands: impact on control and elimination of schistosomiasis in marshland regions along the Yangtze River, China. Infectious Diseases of Poverty, 6(1), 72.

51. Tan Y, Wang Y, Wang Y, Xu D, Huang Y, Wang D, Wang G, Rensing C, Zheng S. 2018. Novel mechanisms of selenate and selenite reduction in the obligate aerobic bacterium Comamonas testosteroni S44. Journal of Hazardous Materials, 359, 129-138.

52. Toro-Londono M, Bedoya-Urrego K, Garcia-Montoya G, Galvan-Diaz A, Alzate J. 2019. Intestinal parasitic infection alters bacterial gut microbiota in children. PeerJ, 7, e6200.

53. Wu HJ, Ivanov II, Darce J, Hattori K, Shima T, Umesaki Y, Littman DR, Benoist C, Mathis D. 2010. Gut-residing segmented filamentous bacteria drive autoimmune arthritis via $\mathrm{T}$ helper 17 cells. Immunity, 32(6), 815-827.

54. Yuan Z, Yan W, Wen C, Zheng J, Yang N, Sun C. 2020. Enterotype identification and its influence on regulating the duodenum metabolism in chickens. Poultry Science, 99(3), 1515-1527. 
55. Zhang XS, Li J, Krautkramer KA, Badri M, Battaglia T, Borbet TC, Koh H, Ng S, Sibley RA, Li Y, Pathmasiri W, Jindal S, Shields-Cutler RR, Hillmann B, Al-Ghalith GA, Ruiz VE, Livanos A, van't Wout AB, Nagalingam N, Rogers AB, Sumner SJ, Knights D, Denu JM, Li H, Ruggles KV, Bonneau R, Williamson RA, Rauch M, Blaser MJ. 2018. Antibiotic-induced acceleration of type 1 diabetes alters maturation of innate intestinal immunity. eLife, 7, e37816.
56. Zhang Y, Wang Y, Jiang Y, Pan W, Liu H, Yin J, Shen Y, Cao J. 2016. T follicular helper cells in patients with acute schistosomiasis. Parasites \& Vectors, 9(1), 321.

57. Zhao Y, Yang S, Li B, Li W, Wang J, Chen Z, Yang J, Tan H, Li J. 2019. Schistosoma japonicum alterations of the mice gut microbiome via ova-induced granuloma. Frontiers in Microbiology, 10, 352.

58. Zou L, Ruan S. 2015. Schistosomiasis transmission and control in China. Acta Tropica, 143, 51-57.

Cite this article as: Jiang Y, Yuan Z, Shen Y, Rosa BA, Martin J, Cao S, Zhou Y, Mitreva M \& Cao J. 2021. Alteration of the fecal microbiota in Chinese patients with Schistosoma japonicum infection. Parasite 28, 1.

\section{PARASTE}

An international open-access, peer-reviewed, online journal publishing high quality papers on all aspects of human and animal parasitology

Reviews, articles and short notes may be submitted. Fields include, but are not limited to: general, medical and veterinary parasitology; morphology, including ultrastructure; parasite systematics, including entomology, acarology, helminthology and protistology, and molecular analyses; molecular biology and biochemistry; immunology of parasitic diseases; host-parasite relationships; ecology and life history of parasites; epidemiology; therapeutics; new diagnostic tools.

All papers in Parasite are published in English. Manuscripts should have a broad interest and must not have been published or submitted elsewhere. No limit is imposed on the length of manuscripts.

Parasite (open-access) continues Parasite (print and online editions, 1994-2012) and Annales de Parasitologie Humaine et Comparée (1923-1993) and is the official journal of the Société Française de Parasitologie. http://parasite.edmgr.com/ 